Research Article

\title{
Development, Performance, and Microscopic Analysis of New Anchorage Agent with Heat Resistance, High Strength, and Full Length
}

\author{
Xiaohu Liu $\mathbb{D}^{1},{ }^{1}$ Zhishu Yao $\mathbb{D}^{1},{ }^{1}$ Weipei Xue $\mathbb{D}^{1,2}$ and Xiang Li $\mathbb{D}^{1}$ \\ ${ }^{1}$ School of Civil Engineering and Architecture, Anhui University of Science and Technology, Huainan 232001, China \\ ${ }^{2}$ Post-Doctoral Research Station of Safety Science and Engineering, Anhui University of Science and Technology, \\ Huainan 232001, China
}

Correspondence should be addressed to Zhishu Yao; zsyao@aust.edu.cn

Received 3 February 2019; Revised 23 March 2019; Accepted 27 March 2019; Published 24 April 2019

Guest Editor: Alena Šišková

Copyright (c) 2019 Xiaohu Liu et al. This is an open access article distributed under the Creative Commons Attribution License, which permits unrestricted use, distribution, and reproduction in any medium, provided the original work is properly cited.

\begin{abstract}
To solve the difficult problems of failure of pretensioned bolt supports under high ground pressure and temperature, a new kind of anchorage agent with excellent performance is developed. First, the selection and compounding of raw materials were conducted. The new anchorage agent was obtained by modifying the PET resin by mixing with a phenolic epoxy vinyl ester resin (FX-470 resin) and adding a KH-570 silane coupling agent. Then, the viscosity, thermal stability, compressive strength under different temperatures, and anchorage capacity of the new anchorage agent were tested. Moreover, the best proportion ratio of anchorage agent by mixing resin : coarse stone powder : fine stone powder : accelerator : curing agent: KH-570=100:275:275:1:32.5:1 is obtained. The test results showed that, with the addition of a KH-570 silane coupling agent, the viscosity decreased significantly, thereby solving the difficult technical problems of pretensioned bolt supports in full-length anchorage support. Compared with the conventional anchorage agent, the compressive strength of the new anchorage agent increased by $20.4,82.5,118.2$, and $237.5 \%$ at $10,50,80$, and $110^{\circ} \mathrm{C}$, respectively, and the anchorage capacity increased by $4.7,8.7,40.2$, and $62.9 \%$ at $30,50,80$, and $110^{\circ} \mathrm{C}$, respectively. Finally, the enhancement in compressive strength and heat-resistant mechanism are revealed through microanalysis.
\end{abstract}

\section{Introduction}

With the increase in mining depth and crustal stress every year, the quantity of broken rock mass increases, which leads to a series of problems such as difficulty in roadway maintenance, cost increase, and safety issues $[1,2]$. Fulllength anchorage support can maintain the roadways well [3-5]. However, the emerging technology of full-length anchorage support is not yet popular, and with an increase in mining depth, the ground temperature increases, and the anchoring force of the resin anchor becomes lower than the theoretical value [6]; therefore, the anchoring safety decreases.

Many scholars have studied the effect of full-length anchor support and temperature on the anchoring force. Zhou et al. studied the shear stress distribution and load transfer at the interface of a full-length bonded bolt and deduced the constitutive model of double exponential curve and the exponential form of the load-displacement curve at the top of the bolt. He established that load-displacement distribution at the interface of the bolt and anchor could be a solution [7]. In Nemcik's study, the nonlinear bond-slip constitutive model is combined with FLAC2D to simulate the failure transmission law of a full-length anchored rock under tension [8]. Hu reported a low-viscosity and highstrength anchoring agent using fine stone powder as an aggregate, increasing the amount of resin to improve the consistency of the anchoring agent and compensating for the decrease in resin strength due to a lack of coarse aggregates by increasing the degree of polymerization of the resin [9]. Fan studied the feasibility of introducing a bisphenol A structural reinforcement resin as an anchorage agent into an 
unsaturated polyester resin to induce high-temperature stability [10]. Lin carried out optimization test and resin simulation research on the shape and size of a full-length anchor bolt and optimized the height, width, and spacing of the cross-ribs of the bolt [11]. Zhang et al. simulated the resin anchor-hold at different temperatures and obtained the temperature around the drill hole can influence the resin anchor-hold [12]. Hu used a combination of laboratory tests and numerical simulation to study the effect of temperature on the anchoring properties of resin anchors [13]. To solve the problem of adaptability of the full-length anchorage agent technology and ensure the strength of the anchoring support in high ground temperatures, it is urgent to develop a new type of heat-resistant, high-strength, and full-length anchoring agent.

Based on the commonly used full-length anchoring agent comprising unsaturated polyester resins as a binder, the optimum raw materials were selected and samples were prepared. The new type of heat-resistant, high-strength, and full-length anchoring agent was developed by mixing a phenolic epoxy vinyl ester resin (FX-470) with modified PET and adding a silane coupling agent (KH-570). Finally, the physical and mechanical properties of the new anchorage agent were tested.

\section{Test}

\subsection{Test Materials}

2.1.1. Resin. The unsaturated polyester resins used in an anchoring agent can be classified into the following types: o-phthalate, phenylene, $\mathrm{m}$-phthalate, and PET. According to $\mathrm{Hu}$ and Wang [14], PET resin is widely used in the production of mine-support materials because of its excellent performance, inexpensiveness, and short gelling time. The liquid index of PET unsaturated polyester resin is shown in Table 1.

In this study, polyblend modification was used to improve the poor temperature resistance of the PET resin and the blend system was solidified under the existing solidifying system of unsaturated polyester resin. Vinyl ester resin combines the advantages of unsaturated polyester resin and epoxy resin. Its epoxy framework imparts excellent heat resistance and corrosion resistance to the resin, which can be solidified using the peroxide curing system [15]. Therefore, a phenol epoxy vinyl ester resin was used to modify the PET resin. The chemical formula of the phenol epoxy vinyl ester resin is shown in Figure 1, and the liquid index is shown in Table 1.

2.1.2. Aggregate. The aggregate in an anchorage agent significantly affects the consistency, strength, and thermal stability of the anchoring agent. In this study, river sand, quartz sand, cement, and stone powder were chosen to carry out the proportion test. It was found that river sand and quartz sand fillers decrease the polymer strength and cause fragmentation, while cement fillers rapidly increase the viscosity of polymer and lower the thermal stability. However, stone powder fillers imparted better strength and
TABLE 1: Liquid index of resin.

\begin{tabular}{lccc}
\hline Type & $\begin{array}{c}\text { Acid value } \\
(\mathrm{KOH}\end{array}$ & Viscosity & $\begin{array}{c}\text { Heat distortion } \\
\text { temperature }\end{array}$ \\
& $\mathrm{mg} / \mathrm{g})$ & $\left(25^{\circ} \mathrm{C}, \mathrm{mPa} \cdot \mathrm{s}\right)$ & $\left({ }^{\circ} \mathrm{C}\right)$ \\
\hline PET & $10-20$ & $550-650$ & $50-55$ \\
FX-470 & $6-18$ & $300-500$ & $165-170$ \\
\hline
\end{tabular}<smiles>[R]C(=C)OCCCOc1ccccc1Cc1ccc(OCCCOC([R])=C)c(OCCCOC([R])C)c1</smiles>

Figure 1: Phenol-aldehyde-epoxy-type vinyl ester resin.

viscosity to the anchorage agent. The main components and grain composition of stone powder are selected as shown in Tables 2 and 3 . Because wet aggregates can destroy the bonding between the binder and aggregate and reduce the strength of the anchoring agent, the aggregate must be dried to $0.1 \%$ or less water content [16].

2.1.3. Curing Agent and Accelerator. As per the requirements of the existing anchoring agent preparation technology, the curing agent used in this study was a mixture of benzoyl peroxide (BPO), calcium carbonate, and ethylene glycol. The content of BPO in the mixture was fixed at $6 \%$, and the amount of curing agent used in the experiment was $5 \%$ of the total weight of the anchoring agent cement. The accelerator used was $N, N$-dimethylaniline (DMA), and the amount was $1 \%$ of the resin mass in the anchoring agent cement.

2.1.4. Silane Coupling Agents. The silane coupling agent is a kind of organosilicon compound that contains both carbon and silicon functional groups. It is an organic polymer composite that plays the role of an auxiliary for reinforcing, increasing the viscosity, compatibilizing, and imparting moisture resistance. In this paper, the polymer is unsaturated polyester and a silane coupling agent (KH-570) is selected [17]. The compatibility and reinforcement of this silane coupling agent are mainly used to increase the amount of stone powder in the anchoring cement and reduce the consistency of anchoring cement. However, there is an ideal amount of coupling agent to produce the ideal effect $[17,19]$. The amount of silane coupling agent $(\mathrm{KH}-570)$ in this test ranges from 0.5 to $2 \%$ by weight of the resin.

2.2. Test Method. The existing conventional full-length anchoring agent is composed of the resin, stone powder, accelerator, and curing agent. Its composition ratio is PET resin/coarse stone powder/fine stone powder/accelerator/ 
TABle 2: Main composition of stone powder.

\begin{tabular}{lcccc}
\hline $\mathrm{CaO}(\%)$ & $\mathrm{SiO}_{2}(\%)$ & $\mathrm{Al}_{2} \mathrm{O}_{3}(\%)$ & $\mathrm{MgO}_{(\%)}$ & $\mathrm{Fe}_{2} \mathrm{O}_{3}(\%)$ \\
\hline 50.7 & 19.9 & 5.6 & 2.5 & 0.6 \\
\hline
\end{tabular}

TABLE 3: Screening of stone powder particles.

\begin{tabular}{lccccc}
\hline & $10-50$ mesh & $50-100$ mesh & $100-150$ mesh & $150-200$ mesh & $200-325$ mesh \\
\hline Coarse stone powder (\%) & 95.1 & 2.53 & 1.83 & 0.48 & 0.06 \\
Fine stone powder (\%) & 10.7 & 17.2 & 10.6 & 44.1 & 17.4 \\
\hline
\end{tabular}

curing agent $=100: 200: 200: 1: 25$. In order to adapt to the full-length anchorage construction technology and reduce the pushing resistance of the anchor during construction, the method of reducing the content of stone powder is usually used to reduce the self-consistency of the anchoring agent. On the other hand, with the increase in the amount of resin, the compressive strength of the anchoring agent decreases after solidification. In addition, the heat resistance of the PET resin in the anchoring agent is generally poor, and it deteriorates with the increase in the amount of the resin.

In view of the existing problems of the conventional fulllength anchoring agent, FX-470 resin and silane coupling agent $\mathrm{KH}-570$ are introduced to improve the performance of conventional anchoring agent. The design and test scheme are shown in Table 4. Based on the China coal industry standard MTl46.1.2011 [20] and GB/T 2567.2008 [21], the viscosity, thermal stability, compressive strength, and anchorage capacity of capsule resin are tested.

\section{Experimental Analysis of Physical and Mechanical Properties of Anchoring Agent}

3.1. Viscosity Test. Full-length anchoring support technology requires that the anchorage agent fills the whole anchor hole. If the anchorage agent has a high viscosity, the anchorage resistance will be large, which will lead to the anchorage of the anchor not reaching the required depth and thus greatly reducing the support. Therefore, a reasonable viscosity of the anchorage agent is necessary.

Test Method. The hollow cone for determining the standard consistency of cement and the circular mould for determining the setting time of cement according to MT 146.12011 are used [20]. Record the sinking depth of the hollow cone within $1 \mathrm{~min}$. The experimental results are shown in Figure 2.

As shown in Figure 2, A1 is a conventional full-length anchoring agent. The proportion of stone powder in group $\mathrm{B}$ and group $\mathrm{C}$ is increased, and $\mathrm{KH}-570$ is added at the same time. Compared to the viscosity of B1-B3 or B5-B7 in group $\mathrm{B}$, it can be concluded that when the ratio of resin to stone powder is fixed, the consistency of the anchoring agent decreases with the increase in the amount of KH-570. By comparing B1 and B5 with the condition of the same amount coupling agent, the higher the content of the stone powder, the smaller is the consistency value; compared to the viscosity of $\mathrm{C} 1-\mathrm{C} 6$ in group $\mathrm{C}$, it can be concluded that with the increase in the proportion of FX-470 resin in the mixed resin, the consistency of the anchoring agent decreases because FX-470 resin has a lower viscosity than PET resin; therefore, with increasing FX-470 resin content with the same ratio of resin to stone powder, the consistency deteriorates. By adjusting the amount of silane coupling agent $\mathrm{KH}-570$, the proportion of stone powder in the anchoring agent can be increased while the consistency of the anchorage agent can be reduced at the same time. The consistency value of full-length anchoring agent should be 50-60 mm. The test results show that B2, B6, B7, and C1-C4 in group B are suitable for full-length anchoring support.

3.2. Thermal Stability Test. As supporting material, the storage period of the anchorage agent should not be less than three months. The thermal stability directly affects the storage time of the anchoring agent at room temperature, so it is an important index of anchoring agent performance. The test method is as follows [20]: the anchorage agent is heated in a 101A-2 electric drying oven with forced convection and maintained for $20 \mathrm{~h}$ at $(80 \pm 2)^{\circ} \mathrm{C}$. After removal, it is placed for $4 \mathrm{~h}$ at $(22 \pm 1)^{\circ} \mathrm{C}$. The consistency value of the observed specimens, which is greater than $16 \mathrm{~mm}$, is normal.

Because the influence of the aggregate on the thermal stability was considered and determined at the material selection stage, the new anchoring agent is mainly used to test the influence of $\mathrm{FX}-470$ resin and $\mathrm{KH}-570$ on the thermal stability of anchorage agent. In this paper, B6, C3, and C6 are selected to carry out the thermal stability test. As shown in Table 5 , the viscosity is greater than $16 \mathrm{~mm}$ and the thermal stability performance is qualified. It can be seen that the introduction of FX-470 resin and $\mathrm{KH}-570$ does not affect the thermal stability of the anchoring agent.

3.3. Compressive Strength Test. In the full-length anchoring support system, the anchoring agent acts as the bond between the bolt and the rock, and its own strength affects the stability of the anchor. The stability of the anchorage agent's strength under different temperatures is verified by performing the compressive strength test. The test method is as follows: three $40 \mathrm{~mm}$ cube blocks were prepared using a standard mould, as shown in Figure 3. After curing at a standard temperature for more than $24 \mathrm{~h}$, the specimen was placed in a 101A-2 electric drying oven with forced convection. The test blocks were heated at different temperatures for more than $6 \mathrm{~h}$ to ensure that the temperatures 
TABLE 4: Test proportion of new resin anchorage agent.

\begin{tabular}{|c|c|c|c|c|c|c|c|}
\hline Type & PET & FX-470 & Coarse stone powder & Fine stone powder & KH-570 & Accelerator & Curing agent \\
\hline $\mathrm{A} 1$ & 100 & 0 & 200 & 200 & 0 & 1 & 25 \\
\hline B1 & 100 & 0 & 250 & 250 & 0.5 & 1 & 30 \\
\hline B2 & 100 & 0 & 250 & 250 & 1 & 1 & 30 \\
\hline B3 & 100 & 0 & 250 & 250 & 1.5 & 1 & 30 \\
\hline B4 & 100 & 0 & 250 & 250 & 2 & 1 & 30 \\
\hline B5 & 100 & 0 & 275 & 275 & 0.5 & 1 & 32.5 \\
\hline B6 & 100 & 0 & 275 & 275 & 1 & 1 & 32.5 \\
\hline B7 & 100 & 0 & 275 & 275 & 1.5 & 1 & 32.5 \\
\hline B8 & 100 & 0 & 275 & 275 & 2 & 1 & 32.5 \\
\hline $\mathrm{C} 1$ & 80 & 20 & 275 & 275 & 1 & 1 & 32.5 \\
\hline $\mathrm{C} 2$ & 70 & 30 & 275 & 275 & 1 & 1 & 32.5 \\
\hline $\mathrm{C} 3$ & 50 & 50 & 275 & 275 & 1 & 1 & 32.5 \\
\hline $\mathrm{C} 4$ & 30 & 70 & 275 & 275 & 1 & 1 & 32.5 \\
\hline C5 & 20 & 80 & 275 & 275 & 1 & 1 & 32.5 \\
\hline C6 & 0 & 100 & 275 & 275 & 1 & 1 & 32.5 \\
\hline
\end{tabular}

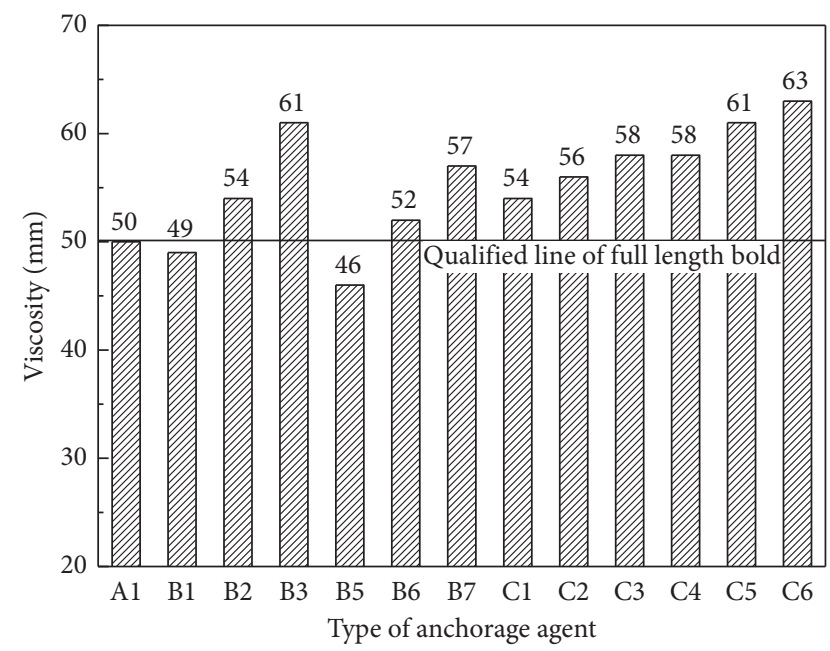

FIgURE 2: Variation in viscosity for different types of anchorage agents.

TABLE 5: Thermal stability test.

\begin{tabular}{llll}
\hline Type & B6 & C3 & C6 \\
\hline Viscosity $\left(80^{\circ} \mathrm{C} / 16 \mathrm{~h}\right) \mathrm{mm}$ & 35 & 37 & 38 \\
\hline
\end{tabular}

inside and outside of the specimen were the same. The compressive strength was measured on a universal material testing machine immediately after removing the specimen from the oven so that the specimen temperature does not change by more than $3^{\circ} \mathrm{C}$. The temperature of the test piece was measured using an F8380 infrared thermometer. The test results are shown in Figures 4 and 5.

As shown in Figure 4, when the coupling agent KH-570 is added to the group B anchoring agent, the proportion of stone powder becomes higher than that of conventional fulllength anchorage agent A1 and the compressive strength significantly increases. Compared to the compressive strength of B1-B4 or B5-B8, with the increase in the amount of the silane coupling agent $\mathrm{KH}-570$ in the anchoring agent,

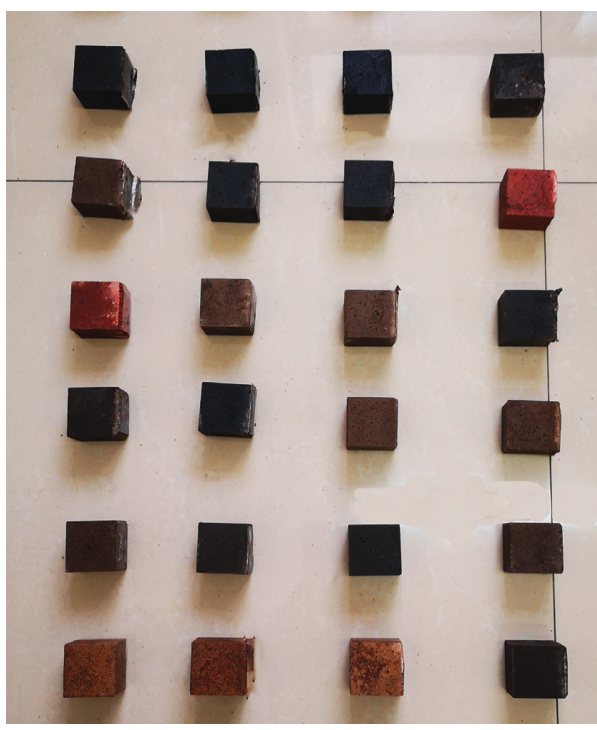

Figure 3: Cube blocks.

the compressive strength increased slightly first at a rate of $3-4 \%$. Then, when the content of silane coupling agent reach $1.0 \%$ of the resin mass, the strength of the anchoring agent did not increase. It can be seen that adding $0.5 \%-1.0 \%$ coupling agent can improve the bonding between the resin and stone powder in the anchoring agent, and the addition of an excessive amount will not improve the compressive strength of the anchoring agent. Therefore, adding an appropriate coupling agent in the anchoring agent can not only adjust the consistency of the cement and optimize the resin ratio but also improve the compressive strength of the anchoring agent itself.

From Figure 5, it can be concluded that the compressive strength of $\mathrm{A} 1$ is $64.4 \mathrm{MPa}$ at $10^{\circ} \mathrm{C}$. The compressive strength decreases by $38.8 \%$ at $50^{\circ} \mathrm{C}, 57.3 \%$ at $80^{\circ} \mathrm{C}$, and $76.7 \%$ at $110^{\circ} \mathrm{C}$. It can be seen that the compressive strength of the A1 anchoring agent is strongly affected by temperature. The B6 anchoring agent is based on A1 ratio to increase the proportion of stone powder and adding $\mathrm{KH}-570$ silane coupling 


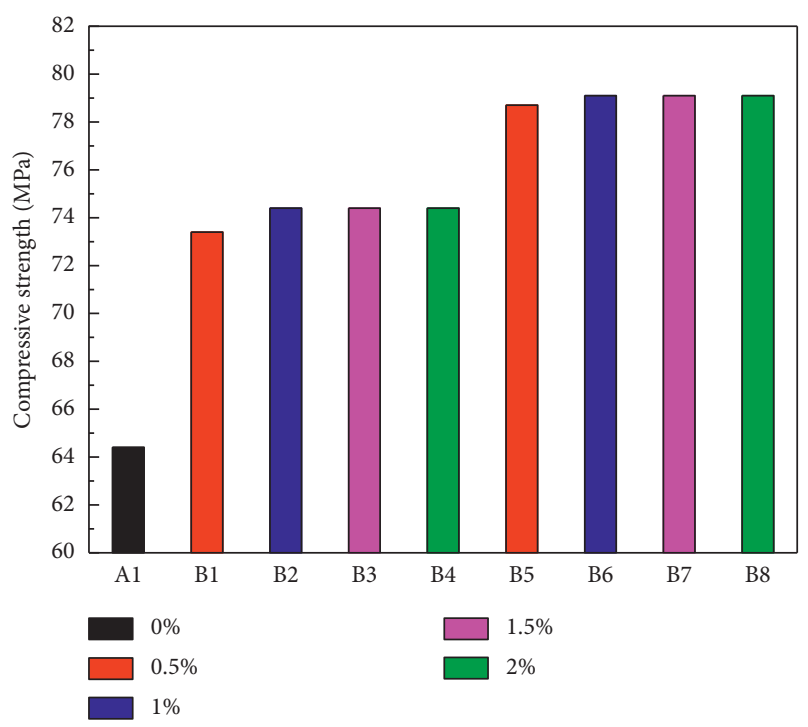

Figure 4: Compressive strength corresponding to different coupling agent contents.

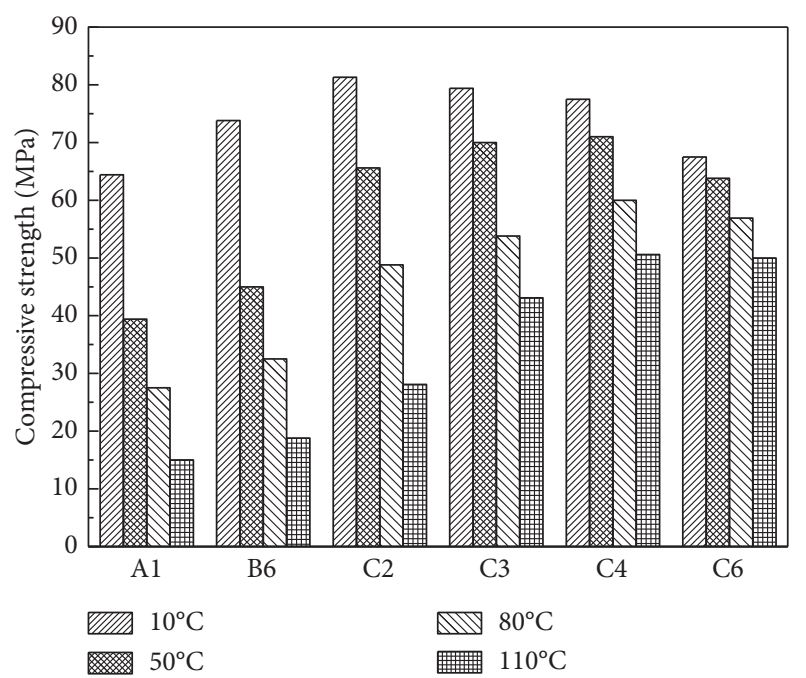

FIGURE 5: Variation of compressive strength with temperature for anchorage agent with different proportions.

agent; thus, the consistency of B6 anchoring agent meets the requirements of full-length anchoring and improves the strength of the anchoring agent at room temperature. However, due to the poor temperature resistance of the PET resin, the performance of the $\mathrm{B} 6$ anchoring agent decreases by $74.6 \%$ at $110^{\circ} \mathrm{C}$. The $\mathrm{C} 6$ anchoring agent is composed of FX-470 resin instead of PET resin. The strength of the anchoring agent at room temperature is $67.5 \mathrm{MPa}$, and its performance remains unchanged up to $50^{\circ} \mathrm{C}$ and decreases by $25.9 \%$ at $110^{\circ} \mathrm{C}$. Samples $\mathrm{C} 2-\mathrm{C} 4$ are mixed modified resin anchoring agents that comprise the FX-470 resin, and their compressive strengths at room temperature are higher than that of the conventional resin anchoring agent. Further, with an increase in the proportion of FX-470 resin, the temperature resistance of the anchoring agent gradually improved. The temperature resistance and compressive strength of the $\mathrm{C} 4$ anchoring agent are excellent. The compressive strength at $10^{\circ} \mathrm{C}$ is $77.5 \mathrm{MPa}$, which decreases by $7.3 \%$ at $50^{\circ} \mathrm{C}, 22.6 \%$ at $80^{\circ} \mathrm{C}$ and $34.6 \%$ at $110^{\circ} \mathrm{C}$. The compressive strength of $\mathrm{C} 4$ increases by $20.4,82.5,118.2$, and $237.5 \%$ over that of $\mathrm{A} 1$ at $10,50,80$, and $110^{\circ} \mathrm{C}$, respectively. It can be seen that the temperature resistance of the $\mathrm{C} 4$ anchoring agent greatly improved after the FX-470 resin was mixed and modified.

3.4. Anchorage Capacity Test. The anchorage force is the most intrinsic parameter to measure the bonding performance of the anchorage agent. In this study, universal material testing machine and temperature-controlled silicone rubber heating belt are used to draw specimens at different temperatures; the test specimens and setup are shown in Figures 6 and 7, respectively. A steel pipe with an outer diameter of $42 \mathrm{~mm}$, inner diameter of $30 \mathrm{~mm}$, and length of $400 \mathrm{~mm}$ and a MSGLW-355 bolt with a diameter of $22 \mathrm{~mm}$ and $450 \mathrm{~mm}$ length were selected for specimen preparation. The anchoring agent is used to seal one end of the steel pipe, and the amount of the anchoring agent is calculated so that the depth of the plug was $50 \mathrm{~mm}$. After the plug was solidified, the anchor bolt was anchored into the steel pipe with a hand-held pneumatic drill. The anchoring depth is $350 \mathrm{~mm}$. After solidification, the specimen is cured at a standard temperature $\left(22^{\circ} \mathrm{C}\right)$ for more than $24 \mathrm{~h}$. Then, the specimen is wrapped with a temperature-controlled silicone rubber heating belt and heated for $2 \mathrm{~h}$ to ensure that the temperatures inside and outside the specimen are the same.

The tests of viscosity, thermal stability, and compressive strength show that the group $\mathrm{C}$ anchorage agents have a good consistency and thermal stability, especially in a hightemperature environment. Among group $\mathrm{C}$ specimens, the comprehensive performance of $\mathrm{C} 4$ anchorage agent is outstanding. Therefore, $\mathrm{C} 4$ type and A1 type anchorage agents are selected to test the anchorage force at different temperatures. The experimental results are shown in Figure 8.

As shown in Figure 8, A1 and C4 anchorage specimens are pulled apart at $10^{\circ} \mathrm{C}$, and their anchorage forces are $186 \mathrm{kN}$. Further, the anchorage forces of A1 are $172 \mathrm{kN}$, $161 \mathrm{kN}, 117 \mathrm{kN}$, and $97 \mathrm{kN}$ at $30^{\circ} \mathrm{C}, 50^{\circ} \mathrm{C}, 80^{\circ} \mathrm{C}$, and $110^{\circ} \mathrm{C}$, respectively, while those of $\mathrm{C} 4$ are $180 \mathrm{kN}, 175 \mathrm{kN}, 164 \mathrm{kN}$, and $158 \mathrm{kN}$ at $30^{\circ} \mathrm{C}, 50^{\circ} \mathrm{C}, 80^{\circ} \mathrm{C}$, and $110^{\circ} \mathrm{C}$, respectively. The anchorage capacity of $\mathrm{C} 4$ was thus higher than that of $\mathrm{A} 1$ by $4.7,8.7,40.2$, and $62.9 \%$ at $30^{\circ} \mathrm{C}, 50^{\circ} \mathrm{C}, 80^{\circ} \mathrm{C}$, and $110^{\circ} \mathrm{C}$, respectively. Further, the difference in the anchorage capacity between $\mathrm{C} 4$ and $\mathrm{A} 1$ increases substantially with the temperature. Therefore, $\mathrm{C} 4$ is a heat-resistant anchoring agent with superior performance.

In summary, according to the results of tests for the viscosity, thermal stability, compressive strength, and anchoring force, it is concluded that $\mathrm{C} 4$ is a heat-resistant, high-strength, and full-length anchoring agent. It has a mixed resin/coarse stone powder/fine stone powder/ accelerator/curing agent/KH-570 resin ratio of $100: 275$ : $275: 1: 32.5: 1$, and the ratio of mixed resin is PET/FX-470 


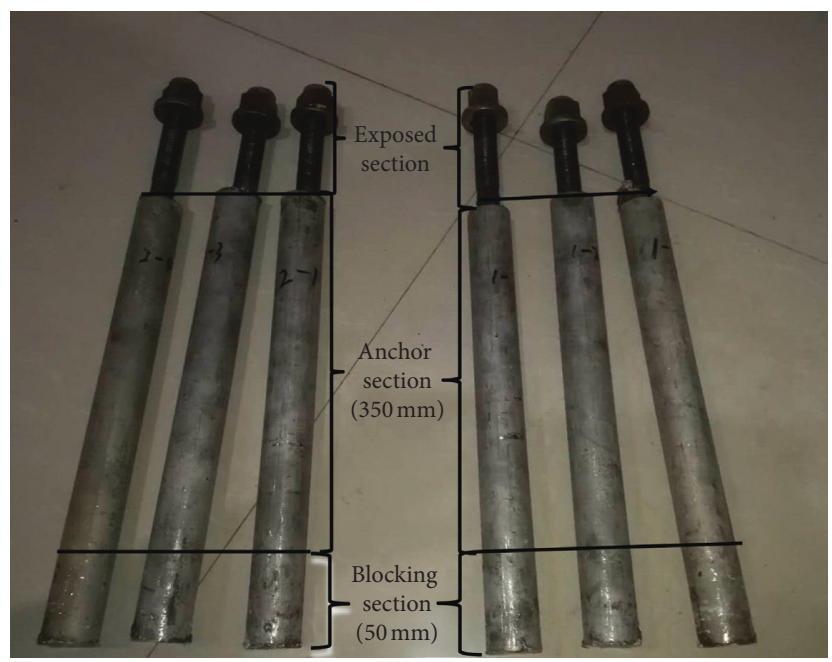

FIGURE 6: Test pieces for testing anchoring force.

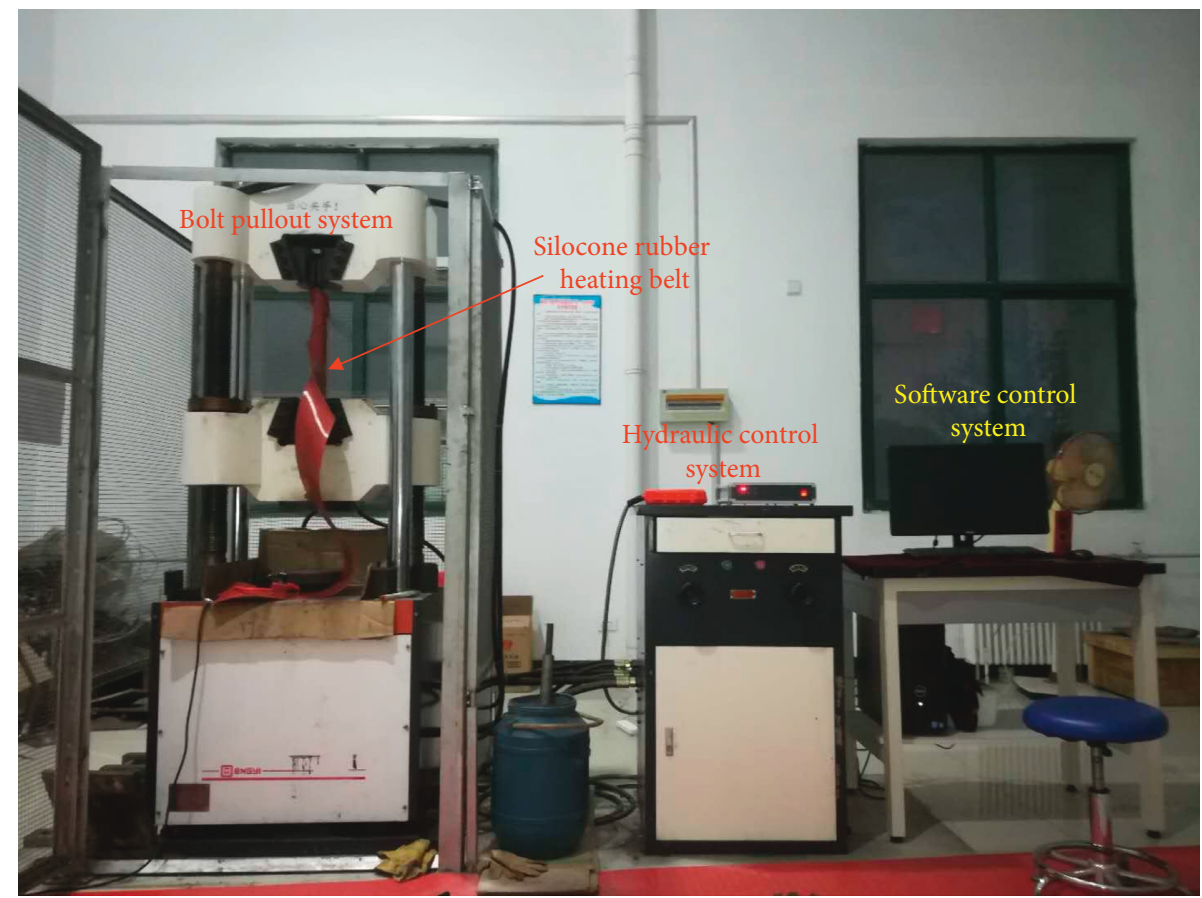

FiguRE 7: Test system for testing anchoring force.

resin $=30: 70$. The new anchorage agent has excellent thermal stability, suitable consistency, and high compressive strength. The compressive strength and anchorage force at a high temperature are obviously superior to those of the existing full-length anchoring agent.

\section{Microscopic Test and Mechanism Analysis of New Resin Anchorage Agent}

Compared with the conventional full-length anchorage agent, the C4 anchorage agent shows excellent performance in physical and mechanical tests. The reasons for this are investigated by performing contact angle test and scanning electron microscopy (SEM) imaging.
4.1. Test of Contact Angle between Resin and Stone Powder. In this study, the contact angle between the PET resin and stone powder was measured using a contact angle tester (SL2000C, Corno Company). Figure 9(a) shows the contact angle between the PET resin and stone powder, and Figure 9(b) shows the contact angle between the stone powder and the PET resin with $1 \%$ silane coupling agent $\mathrm{KH}-570$ added into it. As can be seen, the contact angle decreases by about $20^{\circ}$ from $120.81^{\circ}$ to $101.03^{\circ}$ after the addition of $\mathrm{KH}-570$, and the wettability of the resin and stone powder improved with the addition of the coupling agent. It is explained that when $\mathrm{KH}-570$ is added to the anchorage agent of groups B and $\mathrm{C}$, the proportion of stone powder is increased and the viscosity of anchorage agent is decreased. 


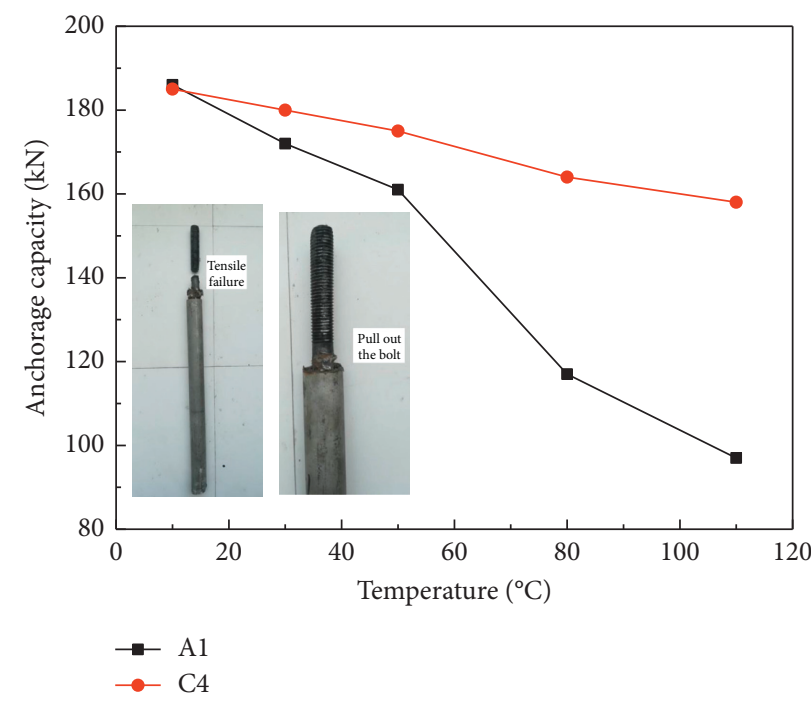

FIGURE 8: Variation in anchorage capacity with temperature for resin capsule.

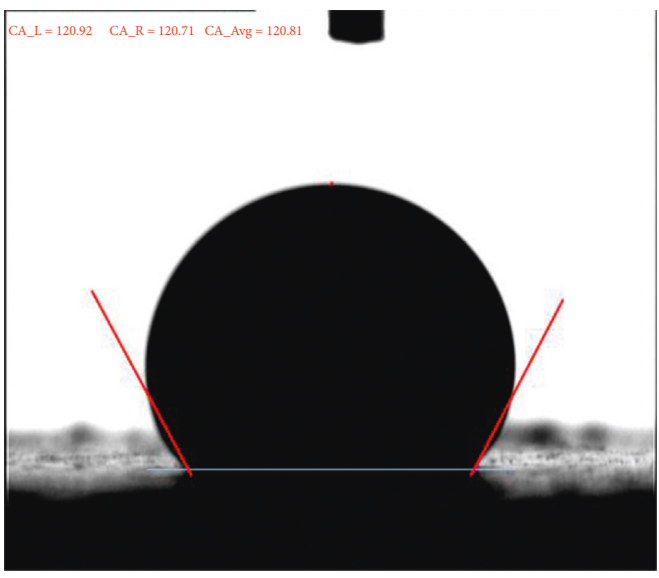

(a)

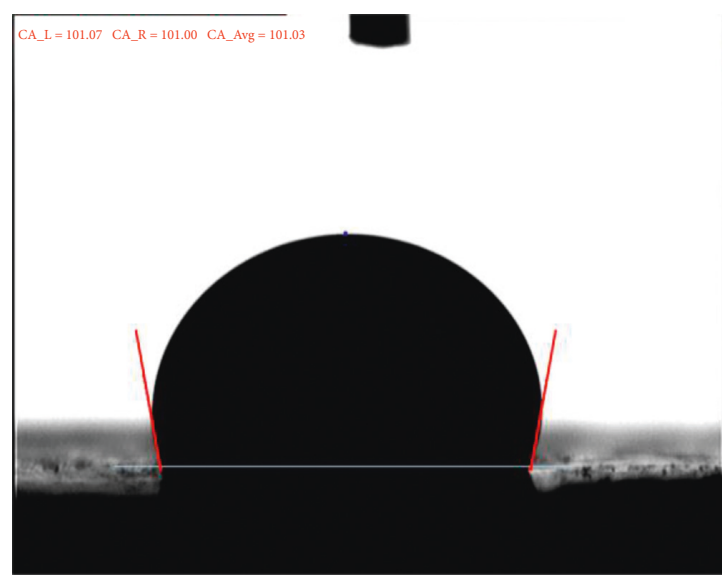

(b)

FIgURE 9: Contact angle. (a) Without adding KH-570 and after adding. (b) 1\% KH-570 into resin anchoring agent.

4.2. SEM Analysis. In this study, SEM is performed to observe the internal fracture surface of the A1 and $\mathrm{C} 4$ anchoring agents after the compressive strength tests. The images are shown in Figure 10.

Figure 10(a) shows a conventional A1 full-length anchorage agent. The filling of fine particles and resin between the coarse particles in the anchoring agent is not compact. The smooth surface of the coarse particles on the shear fracture surface indicates that the resin and particles are not closely bonded. Figure 10(b) shows the C4 anchoring agent, and the resin is closely bound to fine stone powder and is densely packed around coarse grains. The shear fracture surface is rough, and the resin is adsorbed tightly on the surface of the stone powder particles.

4.3. Mechanism Analysis. The wetting effect and chemical bonding of KH-570 between resin and stone powder are verified by performing contact angle measurement and SEM imaging [22]. The contact angle decreased, and the bonding between the resin and stone powder increased with the addition of the coupling agent. The proportion of stone powder in the anchorage agent increased while meeting the viscosity requirement of full-length anchorage support technology, which makes the new anchorage agent more compact and improves its compressive strength.

FX-470 phenolic epoxy vinyl ester resin itself contains unsaturated double bonds and a high-temperature-resistant epoxy skeleton. Under the catalysis of curing agent free radicals, the unsaturated double bonds break to form a solid network with the PET resin. At the same time, the epoxy skeleton itself is embedded in it, which enhances the heat resistance of the anchorage agent after curing. Therefore, on the basis of the original full-length anchorage agent ratio, the heat-resistant full-length anchorage agent with the appropriate strength and consistency can be prepared by adding KH-570 and FX-470 resins. 


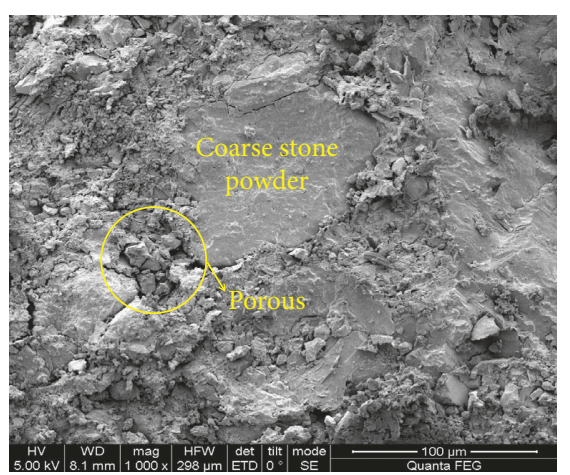

(a)

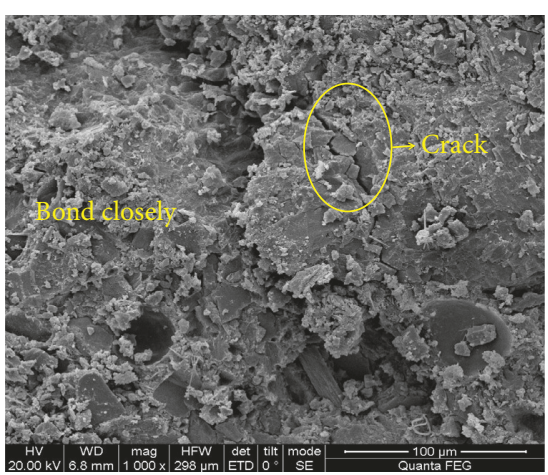

(b)

FIGURE 10: SEM micrographs: the ratio of resin to stone powder is (a) $1: 4$ (A1) and (b) $1: 5.5$ (C4).

\section{Conclusions}

(1) A new type of anchoring agent with heat resistance, high strength, and full length has been successfully developed. The optimum ratio is mixed resin/coarse stone powder/fine stone powder/accelerator/curing agent $/ \mathrm{KH}-570=100: 275: 275: 1: 32.5: 1$, and the ratio of mixed resin is $\mathrm{PET} / \mathrm{FX}-470=30: 70$. The viscosity, thermal stability, compressive strength, and anchorage force results prove that the new anchorage agent has superior physical and mechanical properties, especially in high-temperature environments compared with the conventional anchorage agent.

(2) Experiments show that adding the KH-570 coupling agent in the new anchorage agent has an infiltration effect, which can reduce the amount of resin in the anchorage agent and the viscosity of the anchorage agent. This makes it more suitable for the full-length anchorage support technology and improves the compressive strength of the anchorage agent itself. The reason why the $\mathrm{KH}-570$ coupling agent optimizes the anchorage agent performance is investigated by performing contact angle measurement and SEM imaging.

(3) The results of compressive strength test and anchorage force test under different temperatures show that the introduction of the FX-470 resin into the new anchorage agent to modify the original PET resin can greatly improve the thermomechanical properties of the cured anchorage agent. The compressive strength of the new resin anchorage agent increased by $20.4 \%, 82.5 \%, 118.2 \%$, and $237.5 \%$ at $10^{\circ} \mathrm{C}, 50^{\circ} \mathrm{C}, 80^{\circ} \mathrm{C}$, and $110^{\circ} \mathrm{C}$, respectively, while the anchorage strength increased by $4.7 \%, 8.7 \%, 40.2 \%$, and $62.9 \%$ at $30^{\circ} \mathrm{C}, 50^{\circ} \mathrm{C}, 8^{\circ} \mathrm{C}$, and $110^{\circ} \mathrm{C}$, respectively. The results show that the heat-resistant epoxy group in the FX-470 resin molecule is embedded in the polymer cured by the anchoring agent through the interpolymer reaction between the mixed resins, which improves the overall heat resistance of the anchorage agent.

\section{Data Availability}

The data used to support the findings of this study are included within the article.

\section{Conflicts of Interest}

The authors declare that there are no conflicts of interest regarding the publication of this paper.

\section{Acknowledgments}

This study was supported by the National Natural Science Foundation of China (Nos. 51674006 and 51804006), Anhui Province University disciplines (professional) top-notch talent-funded projects (gxbjZD09), Anhui Provincial College of Natural Science Research Key Project (KJ2018A0098), project funded by the China Postdoctoral Science Foundation (2018M642502), Science Research Foundation for Young Teachers in the Anhui University of Science and Technology (QN2017211), and Science Research for Young and MiddleAged Academic Backbones in Anhui University of Science and Technology.

\section{References}

[1] S.-Q. Yang, M. Chen, H.-W. Jing, K.-F. Chen, and B. Meng, “A case study on large deformation failure mechanism of deep soft rock roadway in Xin'An coal mine, China," Engineering Geology, vol. 217, pp. 89-101, 2017.

[2] H. Wang, P.-Q. Zheng, W.-J. Zhao, and H.-M. Tian, “Application of a combined supporting technology with U-shaped steel support and anchor-grouting to surrounding soft rock reinforcement in roadway," Journal of Central South University, vol. 25, no. 5, pp. 1240-1250, 2018.

[3] X. G. Su, X. J. Du, H. H. Yuan et al., "Research of the thermal stability of structure of resin anchoring material based on 3D CT," International Journal of Adhesion \& Adhesives, vol. 68, pp. 161-168, 2016.

[4] A. Q. Liu and W. J. Ju, "Analysis of shear resisting action of full-length anchored bolt with pre-stress," Coal mining Technology, vol. 17, no. 1, pp. 45-47, 2012. 
[5] C. A. You, "Stress analysis of full-length bonded anchor," Chinese Journal of Rock Mechanics and Engineering, vol. 19, no. 3, pp. 339-341, 2000.

[6] X. W. Feng, Failure Mechanism and Durability Exploration for Fully Bonded Bolting System, China University of Mining and Technology, Xuzhou, China, 2017.

[7] B. S. Zhou, B. T. Wang, C. Y. Yang et al., "Study on load transfer characteristics of wholly grouted bolt," Chinese Journal of Rock Mechanics and Engineering, vol. 36, no. 2, pp. 3774-3780, 2017.

[8] J. Nemcik, S. Ma, N. Aziz, T. Ren, and X. Geng, "Numerical modelling of failure propagation in fully grouted rock bolts subjected to tensile load," International Journal of Rock Mechanics and Mining Sciences, vol. 71, pp. 293-300, 2014.

[9] B. Hu, Study on Mechanical Properties of Resin Capsules for Full-Length Pre-stressed Anchor Bolts, China Coal Research Institute, Beijing, China, 2011.

[10] S. P. Fan, Y. Y. Chen, D. Cui et al., "Study on load transfer characteristics of wholly grouted bolt," Coal Science and Technology, vol. 25, no. 9, pp. 17-19, 1997.

[11] J. Lin, S. Ren, and J. H. Yang, "Laboratory research of resin full-length anchoring bolts dimension optimization," Journal of China Coal Society, vol. 39, no. 6, pp. 1009-1015, 2014.

[12] S. Zhang, P. F. Gou, and H. Fan, "Influence of water and temperature on resin anchor-hold," Journal of Southeast University (Natural Science Edition), vol. 35, pp. 50-54, 2005.

[13] B. Hu, H. P. Kang, J. Lin et al., "Study on influence of temperature on anchorage performance of resin anchored bolt," Journal of Mining \& Safety Engineering, vol. 29, no. 5, pp. 644-649, 2012.

[14] Z. Y. Hu and S. M. Wang, "Systematic study on influencing factors of main performance indexes of resin anchoring agent," Science and Technology Economic Guide, vol. 19, pp. 78-79, 2017.

[15] H. Y. Shi, P. Li, Z. M. Xue et al., "Study on the curing of vinyl ester resin composites," Journal of Materials Engineering, vol. 1, pp. 300-303, 2006.

[16] J. J. Nan, J. Yeon, I. Seung et al., "Effects of curing temperature and hardener type on the mechanical properties of bisphenol F-type epoxy resin concrete," Construction and Building Materials, vol. 156, pp. 933-943, 2017.

[17] L. Chen, Y. Wang, Zia-ud-Din et al., "Enhancing the performance of starch-based wood adhesive by silane coupling agent (KH570)," International Journal of Biological Macromolecules, vol. 104, pp. 137-144, 2017.

[18] X. L. Zhang, H. D. Tang, J. Liao et al., Principles, Synthesis and Application of Silane Coupling Agent, Chemical Industry Press, Beijing, China, 2012.

[19] S. Hu and Z. B. Zeng, "Study on unsaturate polyester resins filled with coupling agent-modified wollastonite," New Chemical Materials, vol. 30, pp. 30-32, 2002.

[20] China Standards Publication, Resin Anchor Bolts-Part 1: Capsules MT 146.1-2011, Standard Press of China, Beijing, China, 2011.

[21] China Standards Publication, Test Methods for Properties of Resin Casting Boby GB/T 2567-2008, Standard Press of China, Beijing, China, 2008.

[22] C. Wang, G. S. Jiao, L. Peng et al., "Influences of surface modification of nano-silica by silane coupling agents on the thermal and frictional properties of cyanate ester resin," Results in Physics, vol. 9, pp. 886-896, 2018. 


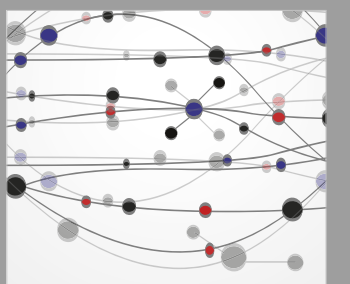

The Scientific World Journal
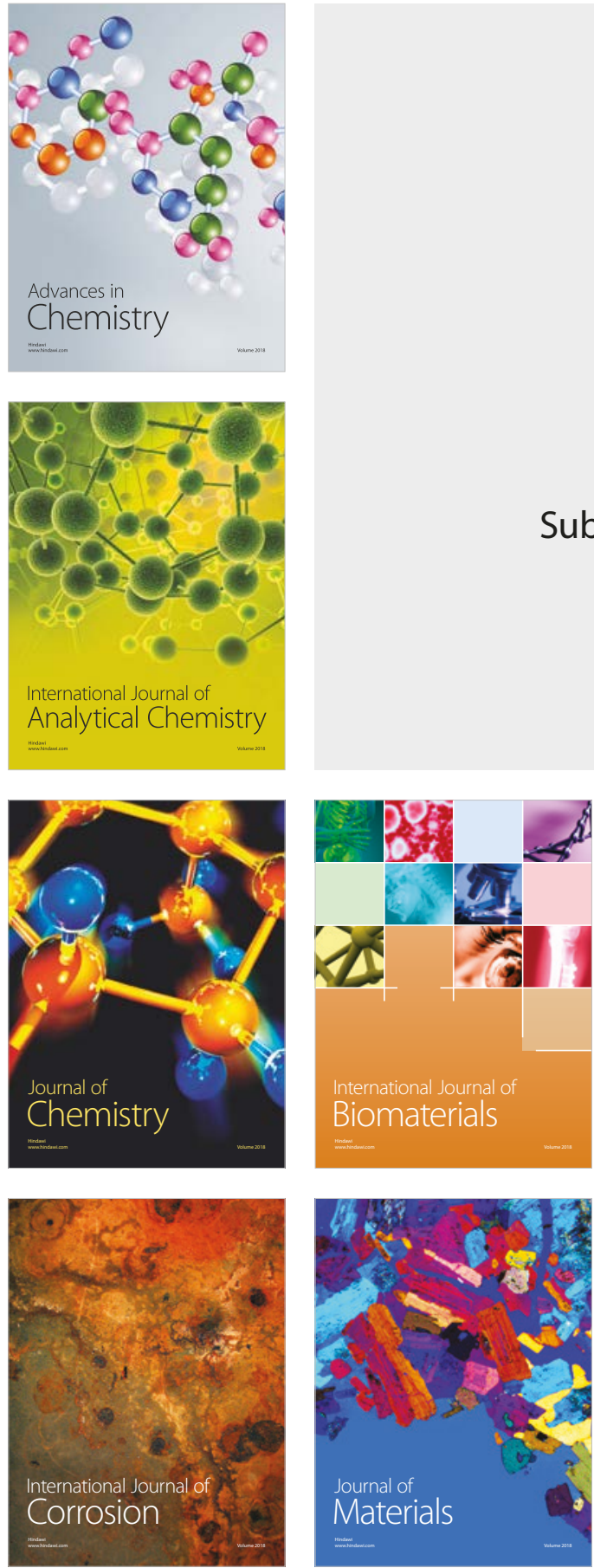

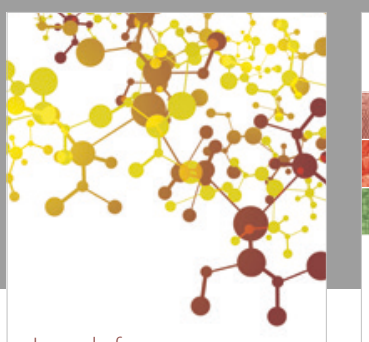

Journal of

Applied Chemistry
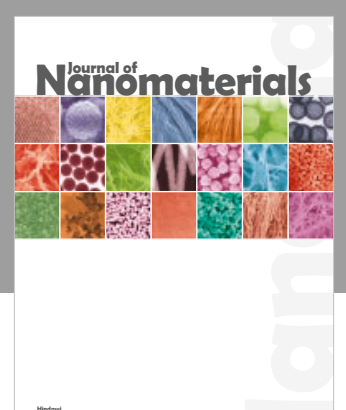

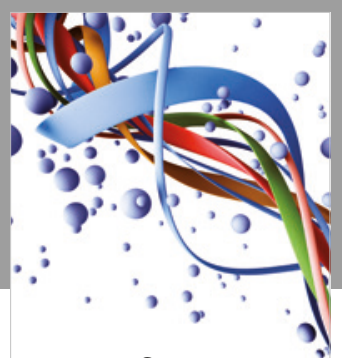

Scientifica

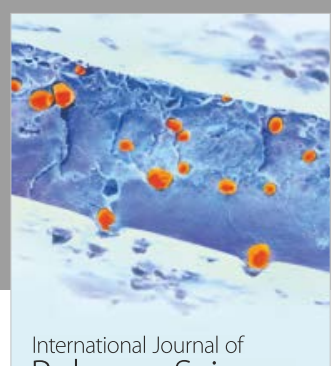

Polymer Science

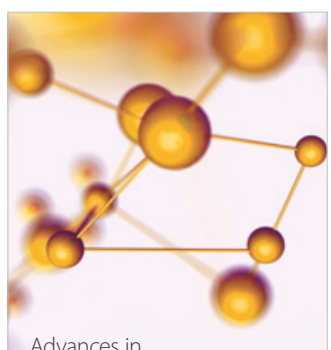

Physical Chemistry
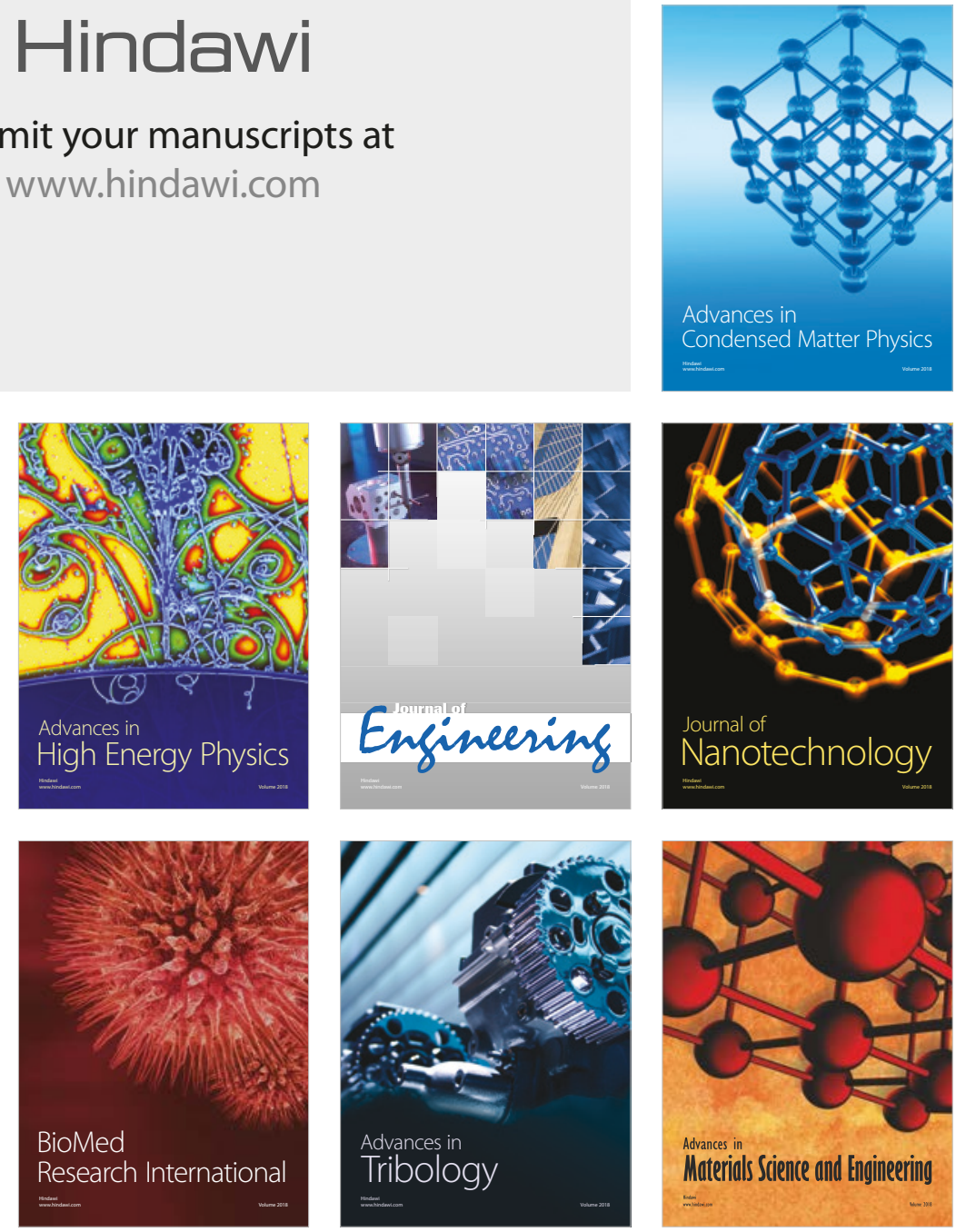